CDU 65.015:616.314

\title{
RACIONALIZAÇÃO DO TRABALHO EM ODONTOLOGIA
}

\author{
Fernando Molinos Pires Filho *
}

\section{$\begin{array}{llllllll}\text { S } & \mathbf{I} & \mathbf{N} & \mathbf{O} & \mathbf{P} & \mathbf{S} & \mathbf{E}\end{array}$}

Conceitua racionalização do trabatho em função do significado das palavras trabalho, ef́icácia, eficiência, produtividade e fadiga, discutindo os aspectos que tem orientado a abordagem do tema.

Para que possamos entender racionalização do trabalho em todo seu seu significado é preciso definir o sentido de certas palavras envolvidas em sua conceituação.

Começamos definindo o que seja trabalho. Normalmente a palavra é usada em dois sentidos. 0 primeiro restrito a execução de uma única tarefa ou operação. 0 segundo abrangendo todas aquelas atividades que somadas caracterizam a ocupação diferenciada de uma pessoa. Assim, ao falarmos em trabalho odontológico estamos nos referindo ao ofício profissional do Cirurgião Dentista, ou seja, a toda uma gama de atividades técnico-científicas, adiministrativas e sociais que interligadas condicionam e caracterizam o desenvolvimento da ocupação do Cirurgião Dentista.
Outro termo que necessita caracterização é a palavra eficácia. ${ }^{2}$

Refere-se ela a capacidade produtiva de uma unidade de trabalho, medidas em termos quantitativos em relação a seus objetivos finais previamente estabelecidos. A unidade de trabalho pode ser representada por uma trabalhador em ação, uma máquina em atividade ou uma organização em funcionamento. Seus objetivos finais podem ser acentar $x$ tijolos, rotular y garrafas ou lançar no comércio $\mathrm{z}$ meercadorias, respectivamente.

Quando estes valores de produção pré-fixados são comparados ao realmante produzido é possível dizer-se da eficácia da unidade produtora. Assim, se nos três exemplos dados o operário acentou $x+20$ tijolos, a máquina rotulou $\mathrm{y}+20$ garrafas $\mathrm{e}$ a organização lançou no comércio $\mathrm{z}$ - 30 mercadorias, modemos dizer que a eficácia desta última é negativa ou que é ineficaz, enquanto que das duas primeiras a eficácia foi 20 unidades suferior a esperada

Isto nos conduz a introdução de outro conceito o de eficiência.

O significado desta palavra envolve a consideração dos custos dos objetivos finais traçados e atingidos.

- Professor do Centro de Pesquisas em Odontologia Social.

R. Fac. Odont. P. A.

13/14: $53-58,1971 / 1972$ 
Assim podemos dizer, no exemplo anterior, que as duas unidades produtoras representadas pelo operário e pela máquina tem a mesma eficácia em relação ao que se destinavam a produzir, porém, não podemos dizer o mesmo quanto a sua eficiência, já que não, sabiamos qual era a previsão para o custo de produção de cada tijolo acentado e de cada garrafa rotulada, e quanto na realidade estes custos atingiram.

Só é possível estabelecer a eficiência de uma unidade produtora quanto se consideram os custos da sua produção. Resumindo, entenda-se eficiência como a relação entre os recursos gastos e os objetivos alcançados e a eficácia como uma relação entre os objetivos alcançados e os esperados.

Necessitamos conceituar ainda $o$ que seja produtividade. ${ }^{3}$

Por produtividade entende-se a relação entre a quantidade de bens produzidos, ou seja o volume de coisas efetuadas por unidade produtora e o tempo gasto para produzi-lo.

Temos então que a produtividade é o quociente da fração Produção/Tempo.

No exemplo anteriormente citado, a produtividade seria o quociente da fração $x$ tijolos acentados/tempo gasto em acentá-los, digamos 4 horas. Na realidade sua produtividade foi maior porque acentou $\mathrm{x}+20 \mathrm{ti}$ jolos no tempo de 4 horas. Mas, também, poderia ter sido maior se tivesse mantido a produção esperada de $x$ tijolos não utilizado todo o tempo de 4 horas de trabalho, isto é, reduzindo o tempo de produção.
Assim a produtividade está na dependência de duas variáveis a produção e o tempo consumido. Ela pode ser elevada quando:

a) aumenta-se o volume de bens produzidos num tempo constante.

b) mantém-se constante o volume de bens produzidos mas reduzse o tempo de produção.

c) aumenta-se o volume de bens produzidos num menor tempo de trabalho.

Fadiga é também uma palavra que deve ter seu significado esclarecido, para que o conceito de racionalização do trabalho seja entendido em toda a sua extensão. ${ }^{5}$

Por muito tempo o termo restringiu-se a capacidade decrescente do individuo para realizar uma tarefa, em conseqüência da mudança físicoquímica ocorrida em seus músculos em decorrência do acúmulo de produtos de degredação.

Hoje, todavia, o termo é mais abrangente a este significado fisiológico, envolve, também, a sensação de cansaço que precede esta diminuição de capacidade para produzir e que atua como um dispositivo de proteção para impedir o esgotamento do indivíduo a ponto de sua potencialida se ver prejudicada sensivelmente.

Feitas estas considerações é cabível introduzir o conceito dado a racionalização do trabalho.

Racionalizar o trabalho é utilizar meios e sistemas que o tornem, ao mesmo tempo, mais eficaz, eficiente, produtivo, menos fatigante e sobretudo mais dignificante.

Justamente para este último aspec- 
to a dignidade do trabalho é que se tem voltado mais recentemente as pesquisas. Antes de analisá-lo consideramos, porém, se 'este «tornar o trabalho mais racional» é uma atitude que encontra significado lógico para o trabalhador.

Parece não haver dúvidas que sim. o homem sempre buscou meios de transformar as energias e materiais do sistema de trabalho com o mínimo de desperdício. Constituindo-se esta busca uma lei natural da espécie.

A questão maior é se não estará sendo a atitude racionalizadora, paulatinamente, embotada no homem moderno.

Analisemos o problema do ângulo de seu desenvolvimento histórico.

Antigamente o homem encontrava tamanhas dificuldades para realização de seu trabalho que era obrigado a permanecer constantemente alerta para encontrar uma forma melhor de produzir. A magnitude dos impecilhos refletia-se proporcionalmente em sua produção, o que condicionava-o a uma preocupação igual no sentido de superá-los.

A atitude racionalizadora estava sempre sendo praticada.

Nesta fese do desenvolvimento o próprio trabalhador ditava sua maneira de trabalhar, criava ele mesmo suas condições de trabalho, idealizava as ferramentas e máquinas de que ia se utilizar. Ele era a unidade produtora.

Com o advento da revolução industrial as condições de trabalho modificaram-se radicalmente.

O trabalhador passou a fazer parte de um sistema onde constitui a- penas um dos elementos. Perde, sua autonomia. Não mais cria suas condições de trabelho mas passa a se adaptar as já existentes. Segue padrões de comportamento pré-estabelecidos. Usa ferramentas e maquinaria já prontas e idealizadas para um desempenho mais fácil e produtivo. Sua principal preocupação é moldarse a tais condições.

Este é um momento histórico em que a tecnologia não é mais produto de racionalização do trabalho de um indivíduo isolado e sim da organização sosial em que vive. A melhoria das condições de trabalho deixam de ser responsabilidade do trabalhador em geral para ser de pessoas especialmente encarregadas disso.

A mudança ocorrida, entretanto, não nos autoriza a afirmar que a atitude racionalizadora esteja sendo embotada no trabalhador moderno.

Ela, simplesmente mudou o campo de aplicação. Inicialmente era toda voltada para o aspecto criativo de instrumentos e métodos de trabalho. $\mathrm{Na}$ fase de desenvolvimento em que vivemos, seu campo de aplicação é o do aprendizado e adaptação a tecnolo. gia existente, sendo, ainda, em menor grau utilizada em sua forma 0 . riginal.

Vejamos, agora, de que forma esta situação nova condiciona o comportamento do trabalhador.

o trabalhador sentiu-se afetado fundamentalmente por esta situação que o coloca passivamente como peça de uma engrenagem complexa.

A tal ponto isto foi observado pelos estudiosos do assunto que as 
pesquisas visando racionalizar o trabalho por longo tempo centradas nos aspectos físicos da execução da tarefa tais como: condições ambientais de iluminação, ventilação, umidade, cor, ruído, etc. que podiam afetar sua capacidade produtiva, deslocaram-se para a consideração sobre a sua motivação e $\mathfrak{a}$ forma como encara o trabalho.

A razão desta concentração na atitude mental do trabalhador baseiase na crença de que ninguém pode estimular ninguém a trabalhar mais eficazmente, a menos que saiba como essa pessoa é motivada e a que incentivos ela responde.

Anteriormente, supunha-se que 0 trabalhador devia ser estudado como uma unidade isolada que, com relação a certos aspectos importantes, ele se assemelhava a uma máquina, cuja eficiência poderia ser estimada cientificamente e que os principais fatores a influenciá-la eram:

a) movimentos dispendiosos e ineficientes na execução do trabalho.

b) fadiga, que se acreditava ser um estado físico-químico do corpo, onde havia acúmulo de toxinas.

c) deficiências no ambiente físico, tais como iluminação pobre, aquecimento inadequado, umidade excessiva e assim por diante.

As premissas que fundamentavam essas experiências eram da Psicologia Industrial fundada por Taylor, Frank Gilberth e seus numerosos sucessores. 4
Todavia, com as experiências levadas a efeito nas oficinas Hawthorne, da General Eletric Company por Elton Mayo essas crenças terminaram por receber severo choque. ${ }^{1}$

Não que as pressuposições anteriores devam ser consideradas como inteiramente falsas, pois há circuns. tâncias em que o indivíduo pode ser, proveitosamente estudado em isolamento e não pode haver dúvida de que más condições ambientais afetam adversamente a eficiência e que estudos de tempo e movimento, reduzindo movimentos ineficientes podem constituir auxílio material, não constituindo, porém, a verdade toda ou mesmo a parte mais importante da verdade. $O$ que as pesquisas em Hawthorne terminariam por demonstrar foi que há «algo mais importante que horas salários ou condições físicas de trabalho - alguma coisa que elevou a produção independentemente do que foi feito com relação às condições físicas».

As pesquisas posteriores mostraram que o comportamento humano do trabalhador não pode ser compreendido puramente em termos de satisfação ou frustações de tendências físicas ou materiais, porque o aspecto social de seu ofício gera novas necessidades que podem ser- tão poderosas, ou mesmo mais poderosas que as anteriores de origem física ou materiais.

Colocado o assunto desta forma, a questão que se impõem para com. preender a conduta do C. Dentista em relação a sua eficácia, eficiência e produtividade no trabalho é:

Afora os aspectos físicos do am-

R. Fac. Odont. P. A. 
biente e os meios de trabalho disponiveis, que fatores de ordem social o estão afetando?

Em primeiro lugar seria desejável determinar qual é a atitude emocional para com o seu trabalho.

A esse respeito assim se referiu o escritor PETER DRUCHVER: «pensar como fazem muitíssimos engenheiros de eficiência social, que funcionar é tudo que importa na vida social, é uma incompreensão dos limites e da importância da pura eficiência. Em sí mesmo a eficiência funcional não é nada, a menos que conheçamos a resposta a questão eficiência para que propósito e a que preço?».

Por exemplo, que razão teria o profissional para se preocupar com racionalização do trabalho se dispõem de horas ociosas em virtude da falta de clientes?

A resposta que for dada reflete a forma com que ele encara seu oficio. Se responder que não há razões para se preocupar é provavelmente, porque considera seu trabalho dentro daquele sentido restrito de execução pura de tarefa. Se apontar entre outras razões as de que, mesmo com horas ociosas, a racionalização lhe seria benéfica porque o auxiliaria a:

1) reduzir a fadiga pelo desenvolvimento de um fluxo suave $e$ equilibrado.

2) obter melhor condição de trabalho para enfrentar uma maior demanda futura.

3) oferecer condições mais favoráveis ao recebimento de atenção por parte de paciente.
4) dispor de mais tempo para executar outras tarefas.

5) obter maior satisfação psicoló gica, é porque vê seu trabalho de forma diferenciada, visualiza o propóstito de seu trabalho não em termos de execução de tarefa, mas como um conjunto de atividades técnicas, administrativas e sociais perfeitamente interligadas.

A seguir precisamos saber até que ponto o C. Dentista desenvolveu o senso de utilidade social que caracteriza sua profissão.

Em outras palavras, que diferença existe para ele atender o caso do paciente ou atender o paciente como uma pessoa doente. Será que ao final de uma jornada de trabalho esta diforenciação não se faz sentir na forma como os pacientes o vêem ou o consideram? E de que maneira esta certeza ou incerteza do julgamento do cliente se reflete em sua atitude perante o trabalho?

Deveríamos buscar, avaliar a intensidade de seu orgulho pela profissão. Sentir a forma com que este sentimento de pertencer a um grupo e zelar pela conceituação de seu nome influi ou afetam sua atitude para com o trabalho que desenvolve.

Precisamos determinar até que ponto o tipo de serviço que dispensa ao paciente atende a utilização de toda sua potencial capacidade profissional e como isto atinge sua necessidade de auto-realização no trabalho.

Tcríamos de detectar o nível de satisfação psicológica que lhe está proporcionando o reconhecimento de 
seu ofício por parte de cliente e o significado que isto pode ter em sua motivação.

Não poderíamos deixar de considerar, como fator influente de sua conduta em relação ao trabalho o «status» que desfruta entre seus colegas de profissão. A capacidade motivacional positiva ou negativa serthe-á transferida na dependência direta de uma situação favorável ou desfavorável que goze no círculo de trabalho.

Estes são alguns dos principais fatores de ordem social que afetam o profissional. Não podemos negar suas existências. $O$ que se torna difícil, porém, é determinar a intensidade com que influenciam a conduta de cada trabalhador em particular.

De qualquer maneira fica claro que, somente buscar meios e sistemas capazes de tornar o trabalho mais eficaz, eficiente e produtivo, sem tentar dignificá-lo, isto é, fazer com que permita que o trabalhador satisfaça suas necessidades psicológicas básicas é de pouca ou de nenhuma valia.
Sob o ponto de vista psicológico, sabemos que todo o comportamento é céusado.

Não importa.o que se pretenda ou ofereça para que o homem faça, ele o faz somente por uma boa e suficiente razão.

Será que nós C. Dentistas, que queremos racionalizar nosso próprio trabalho sabemos exatamente quais são estas razões?

Se não estivermos certos, tudo o que viermos a fazer será pouco frutífero.

Precisamos nos conscientizar, que $r$ : :onalizar o trabalho é antes de mais nada uma atitude mental que para transformar-se em ação exige antes de tudo uma definição de nossos próprios propósitos.

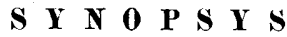

The concept of work Racionalization is given according with the meaning of the words work, efficacy, efïciency, productivity and fatigue, discussing the aspects thant have oriented the approach of the theme.

\section{REFERENCIAS BIBLIOGRÁFICAS}

1. BROWN, J.A. - Psicologia social da indústria. São Paulo, Edl. Atlas, 1967. 240p.

2. CHAVES, Mário M. - Saúde e sistemas. Rio de Janeiro, Escola Nacional de Saúde Fública, 1970. 180p.

3. FOORASTIE, Jean - A produtividade. São Paulo, Difusão Européia do Livro, 1961. 120p.

4. LEHRER, R. -- Simplificação do trabalho. São Paulo, Ibrasa, 1962.

5. MARCH, James G \& SIMON, Herbert A -. Teoria das organizações. Trad. Hugo Wahrich. Rio de Janeiro, Fundação Getúlio Vargas, 1966. 318p. 